\title{
Association of lincRNA-p21 Haplotype with Coronary Artery Disease in a Chinese Han Population
}

\author{
Sai-sai Tang, ${ }^{1,2,3}$ Jie Cheng, ${ }^{1,3}$ Meng-yun Cai, ${ }^{1,2,3}$ Xi-li Yang, ${ }^{4}$ Xin-guang Liu, ${ }^{1,2,3}$ \\ Bi-ying Zheng, ${ }^{3,5}$ and Xing-dong Xiong ${ }^{1,2,3}$ \\ ${ }^{1}$ Institute of Aging Research, Guangdong Medical University, Dongguan 523808, China \\ ${ }^{2}$ Institute of Biochemistry \& Molecular Biology, Guangdong Medical University, Zhanjiang 524023, China \\ ${ }^{3}$ Key Laboratory for Medical Molecular Diagnostics of Guangdong Province, Guangdong Medical University, Dongguan 523808, China \\ ${ }^{4}$ Department of Cardiovascular Disease, The First People's Hospital of Foshan, Foshan 528000, China \\ ${ }^{5}$ Institute of Laboratory Medicine, Guangdong Medical University, Dongguan 523808, China
}

Correspondence should be addressed to Bi-ying Zheng; zby88kr@163.com and Xing-dong Xiong; xiongxingdong@126.com

Received 9 April 2016; Accepted 19 April 2016

Academic Editor: Manfredi Rizzo

Copyright (C) 2016 Sai-sai Tang et al. This is an open access article distributed under the Creative Commons Attribution License, which permits unrestricted use, distribution, and reproduction in any medium, provided the original work is properly cited.

\begin{abstract}
lincRNA-p21 plays an important role in the pathogenesis and progression of coronary artery disease (CAD). To date, the biological significance of polymorphisms in lincRNA-p21 on CAD risk remains unknown. Here we aimed to evaluate the influence of lincRNAp21 polymorphisms on individual susceptibility to CAD. Genotyping of four tagSNPs (rs9380586, rs4713998, rs6930083, and rs6931097) within lincRNA-p21 gene was performed in 615 CAD and 655 controls. The haplotype analysis showed that the haplotype G-A-A-G (rs9380586-rs4713998-rs6930083-rs6931097) was statistically significantly associated with the reduced risk for CAD (OR $=0.78, P=0.023)$. Stratified analysis revealed that $\mathrm{G}-\mathrm{A}-\mathrm{A}-\mathrm{G}$ haplotype was at a significantly lower risk for myocardial infarction (MI) $(\mathrm{OR}=0.68, P=0.010)$. We also found that haplotype $\mathrm{G}-\mathrm{A}-\mathrm{A}-\mathrm{G}$ had a more pronounced decreased risk for premature $\mathrm{CAD}$ or MI subjects $(\mathrm{OR}=0.67, P=0.017$ for premature $\mathrm{CAD}$, and $\mathrm{OR}=0.65, P=0.041$ for premature $\mathrm{MI}$, resp.). Our data provide the first evidence that the G-A-A-G haplotype of lincRNA-p21 is associated with decreased risk of CAD and MI, particularly among premature $\mathrm{CAD} / \mathrm{MI}$ in the Chinese Han population. Further studies with more subjects and in diverse ethnic populations are warranted to clarify the general validity of our findings.
\end{abstract}

\section{Introduction}

Coronary artery disease (CAD) is the world's leading cause of death [1]. Many risk factors have been demonstrated to conduce to the pathogenesis of CAD, including male gender, body fat, smoking, diabetes mellitus, hypertension, high serum cholesterol, and genetic predisposition [2]. Recently, growing studies have focused on the associations of single nucleotide polymorphisms (SNPs) with the risk of CAD, suggesting that genetic polymorphic variations play critical roles on CAD pathogenesis $[3,4]$. Long noncoding RNAs (lncRNAs) represent a novel class of regulatory molecule, which are arbitrarily defined as transcripts of more than 200 nucleotides in length that lack protein-coding potential [5]. LncRNAs are involved in the regulation of gene expression, including epigenetic regulation, transcription, and posttranscriptional regulation [6]. In addition, dysregulation of $\operatorname{lncRNAs}$ can also contribute to the pathogenesis of diverse human diseases, including $\mathrm{CAD}[7,8]$. A growing body of evidence suggests that polymorphisms in IncRNAs gene contribute to CAD and myocardial infarction (MI) susceptibility [9-13].

Among these lncRNAs, lincRNA-p21 contains different motifs which can interact with mRNA, RNA-binding proteins, and miRNAs targets [14-16]. LincRNA-p21 is associated with the pathogenesis of human diseases such as prostate cancer, skin tumor, colorectal cancer, hepatocellular carcinoma, chronic lymphocytic leukemia, and rheumatoid arthritis [1724]. Additionally, lincRNA-p21, a key regulator of vascular 
smooth muscle cells (VSMCs) proliferation and apoptosis, exerts protective effects against neointima formation in injured carotid arteries [25]. Proliferation of VSMCs and the formation of neointima dominate the atherosclerosis lesion development. Thus, lincRNA-p21 might play a crucial role in the pathogenesis and progression of CAD. Recently, a number of studies have focused on the associations of polymorphic variants in lncRNAs with the risk of CAD $[9,12]$. However, whether genetic variants of lincRNA- 21 contribute to the risk of CAD is still unknown. Therefore, the aim of the present study is to analyze the potential association of lincRNAp21 polymorphisms with CAD risk in the Chinese Han population. Our data indicated that the G-A-A-G (rs9380586rs4713998-rs6930083-rs6931097) haplotype of lincRNA-p21 gene was associated with decreased risk of $\mathrm{CAD}$, particularly among early-onset CAD or MI subjects ( $\leq 60$ years old).

\section{Materials and Methods}

2.1. Characteristics of Study Subjects. A total of 1270 subjects (615 CAD and $655 \mathrm{CAD}$-free controls) were recruited from the Affiliated Hospital of Guangdong Medical University and the First People's Hospital of Foshan from March 2011 to October 2014. All study individuals were genetically unrelated Han Chinese. Inclusion and exclusion criteria, diagnosis, and evaluation as well as criteria for CAD, MI, and controls were described previously $[4,26]$.

The early-onset CAD/MI was defined as those cases with the age of less than 60 , according to the previous published studies $[27,28]$. Hypertension was defined if the individual's systolic and/or diastolic blood pressure (DBP) was above 140/90 mmHg [29]. Diabetes mellitus, dyslipidemia, and smoking were defined as described in our previous study [26]. This study was approved by the Ethics Committee of the Affiliated Hospital of Guangdong Medical University and the First People's Hospital of Foshan. All recruited subjects ensured their written informed consent to be included in the study regarding the use of their blood specimens for research studies. The structured questionnaires were administered by interviewers to collect medical information at the enrollment.

2.2. Biochemical Analysis. Blood samples were collected into test tubes containing EDTA as anticoagulant. The sample was separated at $2000 \times \mathrm{g}$ for $15 \mathrm{~min}$ after collection and then stored at $-80^{\circ} \mathrm{C}$. The levels of total cholesterol (TC), triglyceride (TG), low-density lipoprotein cholesterol (LDL$\mathrm{C}$ ), and high-density lipoprotein cholesterol (HDL-C) were determined by an automated chemistry analyzer (Olympus, Japan). The levels of glucose were measured via the glucose oxidase method (Abbott Laboratories, USA).

2.3. DNA Extraction. Genomic DNA was extracted from EDTA anticoagulated venous blood according to the instruction of TIANamp blood DNA extraction kit (TianGen Biotech, China). All of the DNA samples were dissolved into water. The final preparation was stored at $-20^{\circ} \mathrm{C}$.

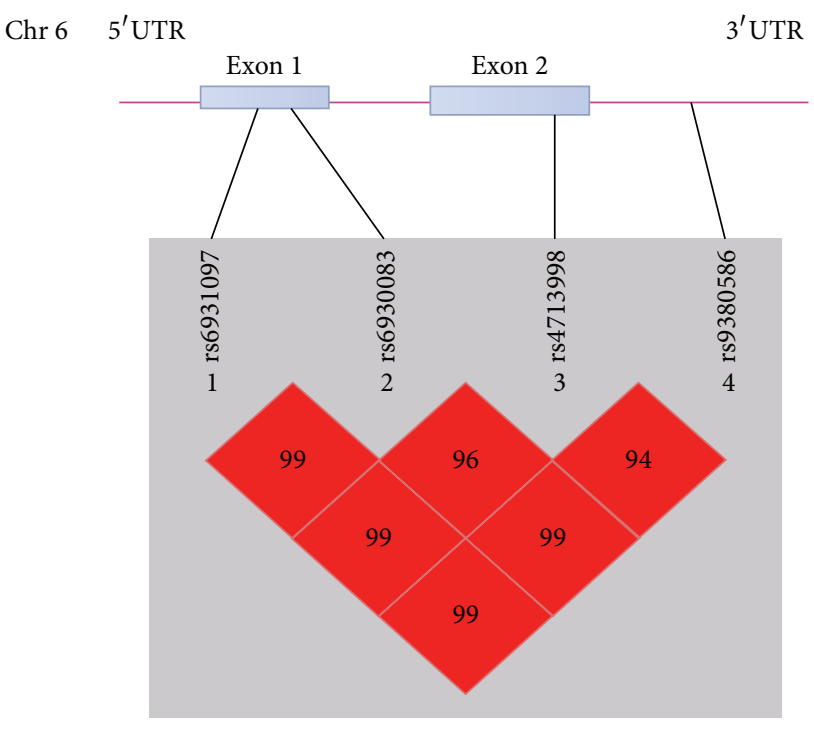

FIGURE 1: Schematic of lincRNA-p21 gene structure. lincRNA-p21 gene is composed of 2 exons which are represented as gray boxes. The lines indicate the locations of single nucleotide polymorphism. $D^{\prime}$ values are plotted to exhibit LD between the four tagSNPs.

2.4. tagSNP Selection and Genotyping. The SNP database of lincRNA-p21 gene in the Han Chinese population was downloaded from the HapMap Project (http://www.hapmap.org/) [30]. The Haploview software (version 4.2) was prerequisites for tagSNPs selection with minor allele frequency (MAF) larger than 0.05 , and linkage disequilibrium (LD) patterns with $r^{2}>0.8$ [31]. Totally, four tagSNPs (rs9380586, rs4713998, rs6930083, and rs6931097) were selected for genotyping. The positions of the four tagSNPs were shown in Figure 1. The $r^{2}$ information for the four tagSNPs and alleles captured accordingly was exhibited in Table S1 in Supplementary Material available online at http://dx.doi.org/10.1155/ 2016/9109743. The haplotypic blocks of the four tagSNPs were estimated by the Haploview software. Then haplotype analysis was performed through the SHEsis software (http://analysis .bio-X.cn/myAnalysis.php) [32].

Genomic DNA was genotyped using PCR-ligase detection reaction method (PCR-LDR) (Shanghai Biowing Applied Biotechnology Company). These sequences of probes and primers were shown in Table S2. The PCR reaction $(20 \mu \mathrm{L})$ contained $50 \mathrm{ng}$ genomic DNA, $0.5 \mu \mathrm{M}$ primer mix, $1 \mathrm{x}$ PCR buffer, $1 \mathrm{U}$ Taq polymerase, $2 \mathrm{mM}$ dNTPs, and $3 \mathrm{mM}$ $\mathrm{MgCl}_{2}$ on the Gene Amp PCR system 9600 (Norwalk, USA). The cycling parameters were carried out as the following procedure: $95^{\circ} \mathrm{C}$ for $2 \mathrm{~min} ; 40$ cycles at $94^{\circ} \mathrm{C}$ for $90 \mathrm{~s}, 56^{\circ} \mathrm{C}$ for $90 \mathrm{~s}$, and $65^{\circ} \mathrm{C}$ for $30 \mathrm{~s}$; and a final extension step at $65^{\circ} \mathrm{C}$ for $10 \mathrm{~min}$. The ligation reaction for PCR product was done in a $10 \mu \mathrm{L}$ volume containing $1 \mu \mathrm{L} 1 \mathrm{x}$ buffer, 2 pmol probe mix, $2 \mathrm{U}$ Taq DNA ligase, and $4 \mu \mathrm{L}$ of PCR product. The LDR parameters were as the following procedure: $95^{\circ} \mathrm{C}$ for $2 \mathrm{~min}$ and 40 cycles at $94^{\circ} \mathrm{C}$ for $15 \mathrm{~s}$ and $50^{\circ} \mathrm{C}$ for $25 \mathrm{~s}$. Then, $1 \mu \mathrm{L}$ LDR reaction product was added into $1 \mu \mathrm{L}$ loading buffer and $1 \mu \mathrm{L}$ ROX. The mixture was then analyzed by the ABI Prism 3730 DNA Sequencer (Applied Biosystems, USA). For ten 
TABLE 1: The characteristics of CAD, MI, and controls.

\begin{tabular}{|c|c|c|c|c|c|}
\hline \multirow{2}{*}{ Variable } & \multirow{2}{*}{ Controls $(n=655)$} & \multirow{2}{*}{$\mathrm{CAD}(n=615)$} & \multirow{2}{*}{$\mathrm{MI}(n=279)$} & \multicolumn{2}{|c|}{$P^{\mathrm{a}}$ versus controls } \\
\hline & & & & $\mathrm{CAD}$ & MI \\
\hline Age (years) & $61.50 \pm 12.50$ & $63.85 \pm 11.71$ & $62.03 \pm 11.90$ & $0.001^{b}$ & 0.552 \\
\hline Sex (male) & $379(57.9 \%)$ & $431(70.1 \%)$ & $217(77.8 \%)$ & $<0.001$ & $<0.001^{\mathrm{b}}$ \\
\hline Smoking & $154(23.5 \%)$ & $341(55.4 \%)$ & $166(59.5 \%)$ & $<0.001$ & $<0.001$ \\
\hline Drinking & $99(15.1 \%)$ & $143(23.3 \%)$ & $72(25.8 \%)$ & $<0.001$ & $<0.001$ \\
\hline Hypertension & $221(33.7 \%)$ & $377(61.3 \%)$ & $171(61.3 \%)$ & $<0.001$ & $<0.001$ \\
\hline Diabetes & $104(15.9 \%)$ & $270(43.9 \%)$ & $127(45.5 \%)$ & $<0.001$ & $<0.001$ \\
\hline Hyperlipidemia & $239(36.5 \%)$ & $423(68.8 \%)$ & $196(70.3 \%)$ & $<0.001$ & $<0.001$ \\
\hline Systolic BP (mm Hg) & $131.83 \pm 19.38$ & $141.06 \pm 18.19$ & $139.53 \pm 19.17$ & $<0.001$ & $<0.001$ \\
\hline Diastolic BP (mm Hg) & $72.78 \pm 10.63$ & $76.29 \pm 10.45$ & $75.78 \pm 11.48$ & $<0.001$ & $<0.001$ \\
\hline FPG (mM) & $5.79 \pm 1.95$ & $6.58 \pm 1.63$ & $6.57 \pm 1.76$ & $<0.001$ & $<0.001$ \\
\hline Triglycerides (mM) & $1.48 \pm 0.81$ & $2.05 \pm 1.02$ & $2.08 \pm 1.01$ & $<0.001$ & $<0.001$ \\
\hline Total cholesterol (mM) & $4.59 \pm 1.15$ & $4.70 \pm 1.24$ & $4.75 \pm 1.23$ & 0.099 & 0.062 \\
\hline HDL cholesterol (mM) & $1.39 \pm 0.67$ & $1.19 \pm 0.38$ & $1.20 \pm 0.44$ & $<0.001$ & $<0.001$ \\
\hline LDL cholesterol (mM) & $2.61 \pm 0.92$ & $3.02 \pm 0.92$ & $3.07 \pm 0.99$ & $<0.001$ & $<0.001$ \\
\hline
\end{tabular}

${ }^{\mathrm{a}}$ Two-sided chi-square test or independent-samples $t$-test.

${ }^{\mathrm{b}} P$ values under 0.05 were shown in bold font.

TABLE 2: Primary information for the polymorphisms in lincRNA-p21 gene.

\begin{tabular}{|c|c|c|c|c|}
\hline Genotyped SNPs & rs9380586 & rs4713998 & rs6930083 & rs6931097 \\
\hline Chr Pos (Genome Build 106) & 36663787 & 36664833 & 36666379 & 36666682 \\
\hline Pos in lincRNA-p21 gene & $3^{\prime}$ UTR & Exon 2 & Exon 1 & Exon 1 \\
\hline $\mathrm{MAF}^{\mathrm{a}}$ for Chinese population (CHB) in HapMap & 0.120 & 0.280 & 0.230 & 0.430 \\
\hline MAF in controls $(n=655)$ & 0.102 & 0.210 & 0.274 & 0.390 \\
\hline$P$ value for $\mathrm{HWE}^{\mathrm{b}}$ test in controls & 0.335 & 0.839 & 0.158 & 0.956 \\
\hline
\end{tabular}

${ }^{\mathrm{a}} \mathrm{MAF}$ : minor allele frequency.

${ }^{\mathrm{b}}$ HWE: Hardy-Weinberg equilibrium.

percent of samples, the PCR was repeated once for quality control. Repeatability of results was $100 \%$.

2.5. Statistical Analysis. Data analysis was performed by using the SPSS computer software (version 21). The haplotype analysis was undertaken using the SHEsis online webserver. Each tagSNP was tested in controls for confirmation with Hardy-Weinberg Expectations (HWE) by a goodness-of-fit $\chi^{2}$ test. Continuous variables between the CAD/MI and control groups were presented as means \pm standard deviation and compared using Student's $t$-test. $\chi^{2}$ test was used for categorical variables in the differences of the demographic characteristics at the CAD/MI and control groups. Logistic regression analysis was used to analyze the association between the risk for CAD/MI and the tagSNPs with adjustment for risk factors of CAD (sex, age, smoking, drinking, diabetes, hyperlipidemia, and hypertension). $P<0.05$ was considered to indicate statistical significance.

\section{Results}

3.1. Characteristics of Study Subjects. The clinical features of individuals recruited in this study were listed in Table 1 and Table S3. The levels of TG and LDL-C were significantly higher in the CAD or MI patients than in the controls (all $P<0.001)$. The patients with CAD or MI had higher levels of diastolic blood pressure, systolic blood pressure, and lower levels of HDL-C (all $P<0.001)$. There were more smokers and drinkers in the CAD or MI cases than in the controls. There was a higher prevalence of subjects with hyperlipidemia, hypertension, or diabetes among the CAD or MI patients. Additionally, the number of male individuals in the CAD or MI cases was much higher than the female individuals. These data showed that alcohol intake, smoking, hyperlipidemia, hypertension, diabetes mellitus, and male gender were the crucial risk factors for developing $\mathrm{CAD} / \mathrm{MI}$ in Chinese population.

3.2. Multivariate Associations of lincRNA-p21 tagSNPs with the Risk of CAD. Four lincRNA-p21 tagSNPs (rs9380586, rs4713998, rs6930083, and rs6931097) were genotyped in CAD $(n=615)$ and control subjects $(n=655)$. The primary information for these polymorphisms was exhibited in Table 2. The observed genotype distribution of four tagSNPs in the controls conformed to the Hardy-Weinberg equilibrium (all $P$ values $\geq 0.05$, Table 2 ), providing no evidence of population stratification within the dataset. To define whether there was a statistically significant increased risk of 
TABLE 3: Multivariate associations of four SNPs in lincRNA-p21 gene with the risk of CAD or MI.

\begin{tabular}{|c|c|c|c|c|c|c|c|}
\hline \multirow[b]{2}{*}{ Type } & \multirow{2}{*}{$\begin{array}{c}\text { Controls } \\
\text { Number (\%) } \\
n=655\end{array}$} & \multicolumn{2}{|c|}{ Cases } & \multicolumn{2}{|c|}{ OR $(95 \% \mathrm{CI})^{\mathrm{a}}$ versus controls } & \multicolumn{2}{|c|}{$P^{\mathrm{a}}$ versus controls } \\
\hline & & $\begin{array}{c}\mathrm{CAD}(\%) \\
n=615\end{array}$ & $\begin{array}{l}\text { MI (\%) } \\
n=279\end{array}$ & CAD & MI & CAD & MI \\
\hline \multicolumn{8}{|c|}{ rs9380586 } \\
\hline G & $1177(89.8)$ & $1104(89.8)$ & $496(88.9)$ & 1 & 1 & & \\
\hline A & $133(10.2)$ & $126(10.2)$ & $62(11.1)$ & $0.97(0.72-1.32)$ & $1.12(0.77-1.64)$ & 0.856 & 0.559 \\
\hline GG & $531(81.1)$ & $497(80.8)$ & $223(79.9)$ & 1 & 1 & & \\
\hline $\begin{array}{l}\mathrm{AA}+\mathrm{AG} \\
r s 4713998\end{array}$ & $124(18.9)$ & 118 (19.2) & $56(20.1)$ & $1.00(0.71-1.39)$ & $1.01(0.66-1.54)$ & 0.986 & 0.981 \\
\hline A & $1035(79.0)$ & $960(78.0)$ & $431(77.2)$ & 1 & 1 & & \\
\hline G & $275(21.0)$ & $270(22.0)$ & $127(22.8)$ & $1.05(0.84-1.31)$ & $1.12(0.77-1.64)$ & 0.686 & 0.231 \\
\hline AA & $408(62.3)$ & $374(60.8)$ & $164(58.8)$ & 1 & 1 & & \\
\hline $\begin{array}{l}\mathrm{AG}+\mathrm{GG} \\
r s 6930083\end{array}$ & $247(37.7)$ & $241(39.2)$ & $115(41.2)$ & $1.01(0.77-1.32)$ & $1.01(0.66-1.54)$ & 0.959 & 0.336 \\
\hline G & $951(72.6)$ & $931(75.7)$ & $425(76.2)$ & 1 & 1 & & \\
\hline A & $359(27.4)$ & $299(24.3)$ & $133(23.8)$ & $0.86(0.69-1.07)$ & $0.83(0.62-1.10)$ & 0.177 & 0.200 \\
\hline GG & $338(51.6)$ & $349(56.7)$ & $160(57.3)$ & 1 & 1 & & \\
\hline $\begin{array}{l}\mathrm{AG}+\mathrm{AA} \\
r s 6931097\end{array}$ & 317 (48.4) & $266(43.3)$ & $119(42.7)$ & $0.82(0.63-1.07)$ & $0.79(0.56-1.11)$ & 0.145 & 0.172 \\
\hline G & 799 (61.0) & $719(58.5)$ & 327 (58.6) & 1 & 1 & & \\
\hline A & $511(39.0)$ & $511(41.5)$ & $231(41.4)$ & $1.12(0.93-1.35)$ & $1.15(0.89-1.47)$ & 0.246 & 0.286 \\
\hline GG & $244(37.3)$ & $204(33.2)$ & $91(32.6)$ & 1 & 1 & & \\
\hline $\mathrm{AA}+\mathrm{AG}$ & $411(62.7)$ & $411(66.8)$ & $188(67.4)$ & $1.16(0.88-1.52)$ & $1.19(0.83-1.69)$ & 0.297 & 0.347 \\
\hline
\end{tabular}

${ }^{\text {a }}$ Adjusted for sex, age, smoking, drinking, hyperlipidemia, hypertension, and diabetes.

TABLE 4: Association between lincRNA-p21 gene haplotypes with the risk of CAD or MI.

\begin{tabular}{|c|c|c|c|c|}
\hline Haplotype $^{a}$ & $\begin{array}{c}\text { Controls } \\
\text { Number (\%) }\end{array}$ & $\begin{array}{c}\text { Cases } \\
\text { Number }(\%)\end{array}$ & OR (95\% CI) & $P$ \\
\hline CAD & $n=655$ & $n=615$ & & \\
\hline$\overline{\text { AAAG }}$ & $132.99(10.2)$ & $124.70(10.1)$ & $1.00(0.77-1.30)$ & 0.994 \\
\hline GAAG & $225.98(17.3)$ & $171.45(13.9)$ & $0.78(0.63-0.97)$ & $0.023^{\mathrm{b}}$ \\
\hline GAGA & $235.99(18.0)$ & $242.27(19.7)$ & $1.12(0.92-1.37)$ & 0.266 \\
\hline GAGG & $440.03(33.6)$ & $421.58(34.3)$ & $1.04(0.88-1.22)$ & 0.685 \\
\hline GGGA & $274.98(21.0)$ & $267.15(21.7)$ & $1.05(0.87-1.27)$ & 0.633 \\
\hline MI & $n=655$ & $n=279$ & & \\
\hline AAAG & $132.99(10.2)$ & $60.70(10.9)$ & $1.09(0.79-1.50)$ & 0.611 \\
\hline GAAG & $225.98(17.3)$ & $69.17(12.4)$ & $0.68(0.51-0.91)$ & $0.010^{\mathrm{b}}$ \\
\hline GAGA & $235.99(18.0)$ & $105.28(18.9)$ & $1.07(0.83-1.38)$ & 0.624 \\
\hline GAGG & $440.03(33.6)$ & $195.85(35.1)$ & $1.08(0.88-1.33)$ & 0.477 \\
\hline GGGA & $274.98(21.0)$ & $123.87(22.2)$ & $1.08(0.85-1.38)$ & 0.521 \\
\hline
\end{tabular}

${ }^{\mathrm{a}}$ The allelic sequence in the haplotypes is in the following order: rs9380586, rs4713998, rs6930083, rs6931097. Haplotype with frequency less than $3 \%$ was pooled and not analyzed.

${ }^{\mathrm{b}} P$ values under 0.05 were shown in bold font.

CAD susceptibility, we conducted an analysis using a logistic regression model, after adjustment for traditional risk factors of CAD and MI (age, gender, drinking, smoking, hypertension, hyperlipidemia, and diabetes; Table 3). No association of these tagSNPs with CAD risk was detected in allelic or genotypic analyses (Table 3). Additionally, there is also no significant difference for allele frequencies and genotype distributions among premature CAD or MI subjects (Table S4).
3.3. Association between the Haplotypes of lincRNA-p21 tagSNPs with the Risk of CAD. Haplotype analyses were carried out to further investigate the combinational effects of these four polymorphisms on CAD risk. As shown in Figure 1, four tagSNPs were located within one haplotypic block. Five common haplotypes with frequency $>3 \%$ accounted for almost all of the haplotype variations (Table 4). We further compared the haplotype frequencies between CAD and 
TABLE 5: Association between lincRNA-p21 gene haplotypes with the risk of premature CAD/MI.

\begin{tabular}{|c|c|c|c|c|}
\hline Haplotype $^{\mathrm{a}}$ & $\begin{array}{c}\text { Controls } \\
\text { Number }(\%)\end{array}$ & $\begin{array}{c}\text { Cases } \\
\text { Number }(\%)\end{array}$ & OR (95\% CI) & $P$ \\
\hline Premature CAD & $n=309$ & $n=238$ & & \\
\hline$\overline{A A A G}$ & $63.00(10.2)$ & 56.77 (11.9) & $1.20(0.82-1.76)$ & 0.344 \\
\hline GAAG & $118.99(19.3)$ & $65.29(13.7)$ & $0.67(0.48-0.93)$ & $0.017^{\mathrm{b}}$ \\
\hline GAGA & $111.00(18.0)$ & $95.23(20.0)$ & $1.15(0.85-1.56)$ & 0.364 \\
\hline GAGG & $193.01(31.2)$ & $167.71(35.2)$ & $1.21(0.94-1.56)$ & 0.142 \\
\hline GGGA & $131.99(21.4)$ & $88.06(18.5)$ & $0.84(0.62-1.14)$ & 0.263 \\
\hline Premature MI & $n=309$ & $n=129$ & & \\
\hline AAAG & $63.00(10.2)$ & $29.68(11.5)$ & $1.17(0.73-1.85)$ & 0.514 \\
\hline GAAG & $118.99(19.3)$ & $34.16(13.2)$ & $0.65(0.43-0.99)$ & 0.041 \\
\hline GAGA & $111.00(18.0)$ & $44.31(17.2)$ & $0.97(0.66-1.42)$ & 0.859 \\
\hline GAGG & $193.01(31.2)$ & $96.85(37.5)$ & $1.36(1.00-1.84)$ & 0.049 \\
\hline GGGA & $131.99(21.4)$ & $48.84(18.9)$ & $0.88(0.61-1.27)$ & 0.484 \\
\hline
\end{tabular}

${ }^{a}$ The allelic sequence in the haplotypes is in the following order: rs9380586, rs4713998, rs6930083, rs6931097. Haplotype with frequency less than $3 \%$ was pooled and not analyzed.

${ }^{\mathrm{b}} P$ values under 0.05 were shown in bold font.

controls. Among the five common haplotypes, only the haplotype G-A-A-G (rs9380586-rs4713998-rs6930083-rs6931097) was found to be associated with a decreased risk for CAD $(\mathrm{OR}=0.78,95 \% \mathrm{CI}=0.63-0.97, P=0.023$, Table 4$) . \mathrm{MI}$ is one of the major adverse outcomes of CAD. Further analysis showed that haplotype G-A-A-G had a significantly lower risk for $\mathrm{MI}(\mathrm{OR}=0.68,95 \% \mathrm{CI}=0.51-0.91, P=0.010$, Table 4$)$. Premature CAD or $\mathrm{MI}$ is known to be the most aggressive form of the disease given no early signs and symptoms. In this study, the decreased risk was more pronounced among premature CAD and MI subjects ( $\leq 60$ years old) carrying haplotype G-A-A-G $(P=0.017, \mathrm{OR}=0.67$ for premature $\mathrm{CAD}$, and $P=0.041, \mathrm{OR}=0.65$ for premature MI, Table 5).

\section{Discussion}

Growing evidences have demonstrated that lincRNA- $p 21$ may participate in the pathogenesis and progression of CAD [25]. However, the biological significance of the lincRNA-p21 polymorphisms on CAD risk is undetermined. In this study, we evaluated the association between lincRNA-p21 tagSNPs and the risk of CAD/MI in the Chinese Han population. We found that the haplotype G-A-A-G was associated with decreased risk of CAD and MI, particularly among premature CAD/MI in Chinese Han population. Our data provided the first evidence that the haplotype G-A-A-G of lincRNA-p21 may be involved in susceptibility to CAD or MI.

Previous investigations have demonstrated that genetic variants in lncRNA gene affect CAD/MI susceptibility. For example, Ishii et al. identified SNPs in MIAT conferring susceptibility to MI [12]. Polymorphisms in lncRNA ANRIL have been found to be associated with the risk of MI [13]. In the present case-control study, we identified that the haplotype G-A-A-G of lincRNA-p21 correlates with the decreased risk of $\mathrm{CAD} / \mathrm{MI}$ in a Chinese population, suggesting that the haplotype G-A-A-G could be a protective factor for CAD/MI. $\mathrm{CAD}$ may be affected by changes related to the function of this genomic region, rather than individual loci per se. There is a possibility that the haplotype is a causal variant, by regulating the gene expression of $\operatorname{lin} c R N A-p 21$, and subsequently contributes to the risk of CAD/MI. The precise mechanisms regarding how the haplotype G-A-A-G of lincRNA-p21 affects $\mathrm{CAD}$ risk need further investigation.

Our stratified analyses revealed that the decreased risk of haplotype G-A-A-G in premature CAD and MI subjects ( $\leq 60$ years old) was more evident. Relative high-level exposure to environmental risk factors and weak immune system in older subjects may account for these. These potential risks of $\mathrm{CAD}$ in older individuals are more likely because of the aging effects instead of the direct genetic effects. Therefore, the lincRNA-p21 haplotype may be more influential in premature CAD/MI.

Several limitations need to be acknowledged in this study. First, our study was performed in a Chinese Han population, and the data should be extrapolated to other regions and ethnic groups cautiously. Second, the sample size of the present study was relatively small. Therefore, enlarging the sample size would make the conclusions more convincing. Finally, further studies in different population may contribute to establish the true significance of the association between this haplotype and the risk of CAD/MI. However, our data provided valuable insights and intriguing information in the development of CAD.

\section{Conclusions}

In summary, our findings indicate that the G-A-A-G haplotype of the lincRNA-p21 gene is associated with a significantly decreased risk of CAD/MI, and the effects are more significant among younger subjects ( $\leq 60$ years old). These results suggest that the G-A-A-G haplotype may contribute to the risk of $\mathrm{CAD} / \mathrm{MI}$, which may be translated into improved $\mathrm{CAD} / \mathrm{MI}$ risk assessment and prevention. However, further 
studies with more subjects and in diverse ethnic populations are warranted to clarify the general validity of our finding.

\section{Competing Interests}

The authors declare that they have no competing interests.

\section{Authors' Contributions}

Xing-dong Xiong conceived and designed the experiments. Sai-sai Tang, Jie Cheng, Meng-yun Cai, Xi-li Yang, and Xinguang Liu performed the experiments. Sai-sai Tang analyzed the data. Sai-sai Tang wrote the paper. Xin-guang Liu have provided significant intellectual contribution to the revision of the paper. Xing-dong Xiong and Bi-ying Zheng revised the paper. All authors critically reviewed the paper and approved its final version.

\section{Acknowledgments}

The study was supported by grants from the National Natural Science Foundation of China (81370456), the Natural Science Foundation of Guangdong Province (2014A030311015), the Science and Technology Planning Project of Dongguan City $(2015108101015,2013108101057)$, and the Foundation for Distinguished Talents in Higher Education of Guangdong (GK1318).

\section{References}

[1] J. Hata and Y. Kiyohara, "Epidemiology of stroke and coronary artery disease in Asia," Circulation Journal, vol. 77, no. 8, pp. 1923-1932, 2013.

[2] P. Greenland, J. S. Alpert, G. A. Beller et al., "2010 ACCF/AHA guideline for assessment of cardiovascular risk in asymptomatic adults: a report of the American College of Cardiology Foundation/American Heart Association Task Force on Practice Guidelines," Journal of the American College of Cardiology, vol. 56, no. 25, pp. e50-e103, 2010.

[3] H. Won, P. Natarajan, A. Dobbyn et al., "Disproportionate contributions of select genomic compartments and cell types to genetic risk for coronary artery disease," PLoS Genetics, vol. 11, no. 10, Article ID e1005622, 2015.

[4] X.-D. Xiong, M. Cho, X.-P. Cai et al., "A common variant in premiR-146 is associated with coronary artery disease risk and its mature miRNA expression," Mutation Research, vol. 761, pp. 1520, 2014.

[5] J. L. Rinn and H. Y. Chang, "Genome regulation by long noncoding RNAs," Annual Review of Biochemistry, vol. 81, pp. 145-166, 2012.

[6] V. A. Moran, R. J. Perera, and A. M. Khalil, "Emerging functional and mechanistic paradigms of mammalian long noncoding RNAs," Nucleic Acids Research, vol. 40, no. 14, pp. 63916400, 2012.

[7] J. C. Scheuermann and L. A. Boyer, "Getting to the heart of the matter: Long non-coding RNAs in cardiac development and disease," The EMBO Journal, vol. 32, no. 13, pp. 1805-1816, 2013.

[8] M. Vausort, D. R. Wagner, and Y. Devaux, "Long noncoding RNAs in patients with acute myocardial infarction," Circulation Research, vol. 115, no. 7, pp. 668-677, 2014.
[9] Y. Liu, H. K. Sanoff, H. Cho et al., "INK4/ARF transcript expression is associated with chromosome 9p21 variants linked to atherosclerosis," PLoS ONE, vol. 4, no. 4, Article ID e5027, 2009.

[10] J. Shanker, P. Arvind, S. Jambunathan, J. Nair, and V. V. Kakkar, "Genetic analysis of the 9p21.3 CAD risk locus in Asian Indians," Thrombosis and Haemostasis, vol. 111, no. 5, pp. 960-969, 2014.

[11] W. Gao, M. Zhu, H. Wang et al., "Association of polymorphisms in long non-coding RNA H19 with coronary artery disease risk in a Chinese population," Mutation Research, vol. 772, pp. 15-22, 2015.

[12] N. Ishii, K. Ozaki, H. Sato et al., "Identification of a novel noncoding RNA, MIAT, that confers risk of myocardial infarction," Journal of Human Genetics, vol. 51, no. 12, pp. 1087-1099, 2006.

[13] W. Ahmed, I. S. Ali, M. Riaz et al., "Association of ANRIL polymorphism (rs1333049:C>G) with myocardial infarction and its pharmacogenomic role in hypercholesterolemia," Gene, vol. 515, no. 2, pp. 416-420, 2013.

[14] J.-H. Yoon, S. Srikantan, and M. Gorospe, "MS2-TRAP (MS2tagged RNA affinity purification): tagging RNA to identify associated miRNAs," Methods, vol. 58, no. 2, pp. 81-87, 2012.

[15] C. J. Wilusz and J. Wilusz, "HuR and translation-the missing linc(RNA)," Molecular Cell, vol. 47, no. 4, pp. 495-496, 2012.

[16] M. Huarte, M. Guttman, D. Feldser et al., "A large intergenic noncoding RNA induced by p53 mediates global gene repression in the p53 response," Cell, vol. 142, no. 3, pp. 409-419, 2010.

[17] M. Işin, E. Uysaler, E. Özgür et al., "Exosomal lncRNA-p21 levels may help to distinguish prostate cancer from benign disease," Frontiers in Genetics, vol. 6, article 168, 2015.

[18] Y. J. Jiang and D. D. Bikle, "LncRNA profiling reveals new mechanism for VDR protection against skin cancer formation," Journal of Steroid Biochemistry and Molecular Biology, vol. 144, part A, pp. 87-90, 2014.

[19] J. R. Hall, Z. J. Messenger, H. W. Tam, S. L. Phillips, L. Recio, and R. C. Smart, "Long noncoding RNA lincRNA-p21 is the major mediator of UVB-induced and p53-dependent apoptosis in keratinocytes," Cell Death and Disease, vol. 6, no. 3, Article ID e1700, 2015.

[20] H. Zhai, A. Fesler, K. Schee, Ø. Fodstad, K. Flatmark, and J. Ju, "Clinical significance of long intergenic noncoding RNA-p21 in colorectal cancer," Clinical Colorectal Cancer, vol. 12, no. 4, pp. 261-266, 2013.

[21] G. Wang, Z. Li, Q. Zhao et al., "LincRNA-p21 enhances the sensitivity of radiotherapy for human colorectal cancer by targeting the Wnt/ $\beta$-catenin signaling pathway," Oncology Reports, vol. 31, no. 4, pp. 1839-1845, 2014.

[22] M. Isin, E. Ozgur, G. Cetin et al., "Investigation of circulating lncRNAs in B-cell neoplasms," Clinica Chimica Acta, vol. 431, pp. 255-259, 2014.

[23] C. F. Spurlock III, J. T. Tossberg, B. K. Matlock, N. J. Olsen, and T. M. Aune, "Methotrexate inhibits NF- $\kappa$ B activity via long intergenic (noncoding) RNA-p21 induction," Arthritis and Rheumatology, vol. 66, no. 11, pp. 2947-2957, 2014.

[24] Y. Ning, F. Yong, Z. Haibin, S. Hui, Z. Nan, and Y. Guangshun, "LincRNA-p21 activates endoplasmic reticulum stress and inhibits hepatocellular carcinoma," Oncotarget, vol. 6, no. 29, pp. 28151-28163, 2015.

[25] G. Wu, J. Cai, Y. Han et al., "LincRNA-p21 regulates neointima formation, vascular smooth muscle cell proliferation, apoptosis, and atherosclerosis by enhancing p53 activity," Circulation, vol. 130, no. 17, pp. 1452-1465, 2014. 
[26] J. Cheng, M. Cho, J.-M. Cen et al., "A TagSNP in SIRT1 gene confers susceptibility to myocardial infarction in a Chinese Han population," PLoS ONE, vol. 10, no. 2, Article ID e0115339, 2015.

[27] T. J. Wang, B. H. Nam, R. B. D’Agostino et al., "Carotid intimamedia thickness is associated with premature parental coronary heart disease: the Framingham Heart Study," Circulation, vol. 108, no. 5, pp. 572-576, 2003.

[28] S. R. Thompson, P. A. McCaskie, J. P. Beilby et al., "IL18 haplotypes are associated with serum IL-18 concentrations in a population-based study and a cohort of individuals with premature coronary heart disease," Clinical Chemistry, vol. 53, no. 12, pp. 2078-2085, 2007.

[29] A. V. Chobanian, G. L. Bakris, H. R. Black et al., "Seventh report of the Joint National Committee on Prevention, Detection, Evaluation, and Treatment of High Blood Pressure," Hypertension, vol. 42, no. 6, pp. 1206-1252, 2003.

[30] J. C. Barrett, B. Fry, J. Maller, and M. J. Daly, "Haploview: analysis and visualization of LD and haplotype maps," Bioinformatics, vol. 21, no. 2, pp. 263-265, 2005.

[31] P. I. W. de Bakker, N. P. Burtt, R. R. Graham et al., "Transferability of tag SNPs in genetic association studies in multiple populations," Nature Genetics, vol. 38, no. 11, pp. 1298-1303, 2006.

[32] Y. Y. Shi and L. He, "SHEsis, a powerful software platform for analyses of linkage disequilibrium, haplotype construction, and genetic association at polymorphism loci," Cell Research, vol. 15, no. 2, pp. 97-98, 2005. 


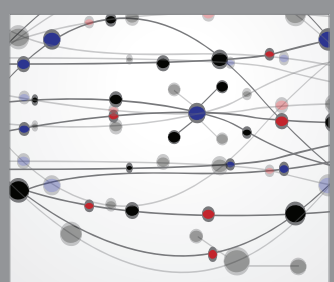

The Scientific World Journal
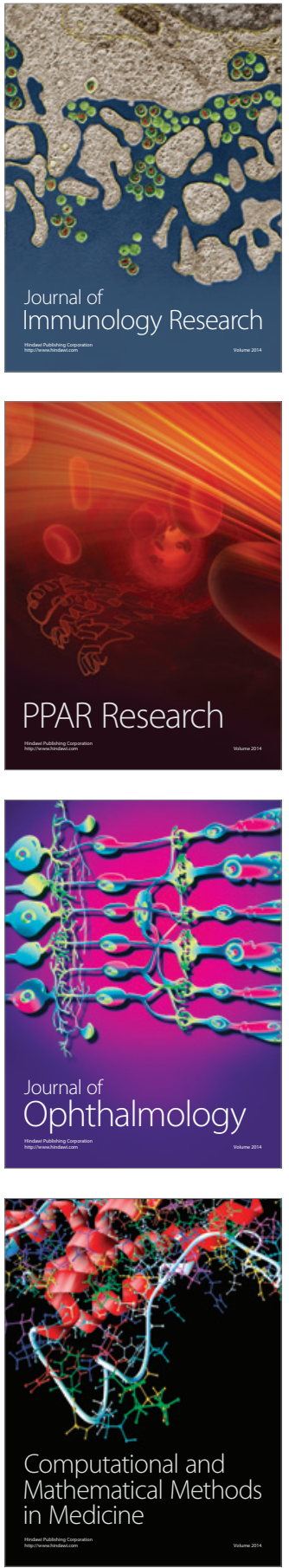

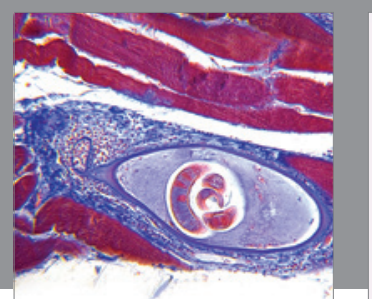

Gastroenterology Research and Practice

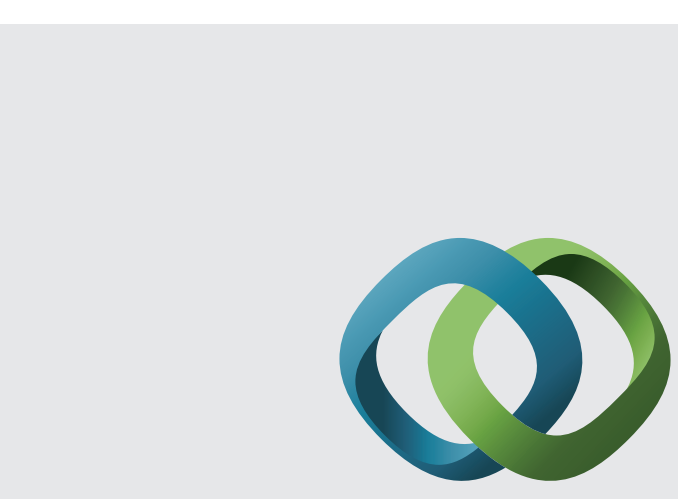

\section{Hindawi}

Submit your manuscripts at

http://www.hindawi.com
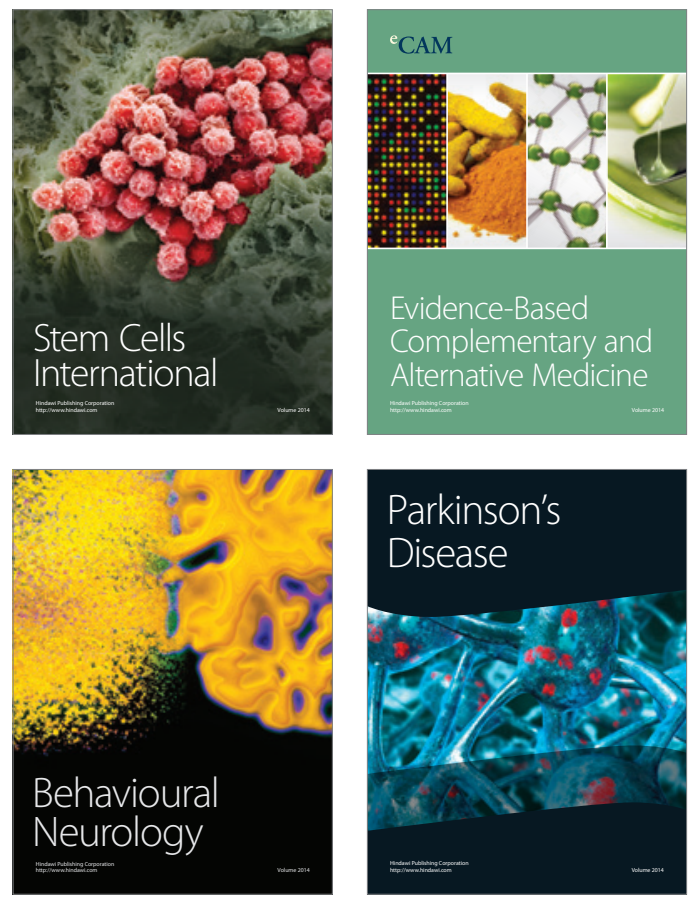
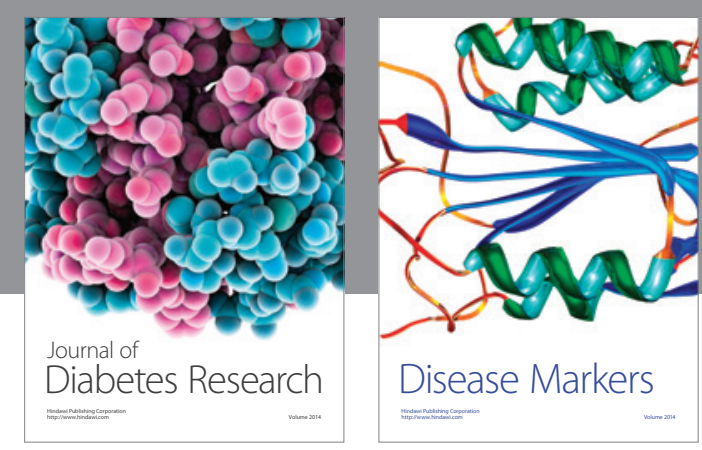

Disease Markers
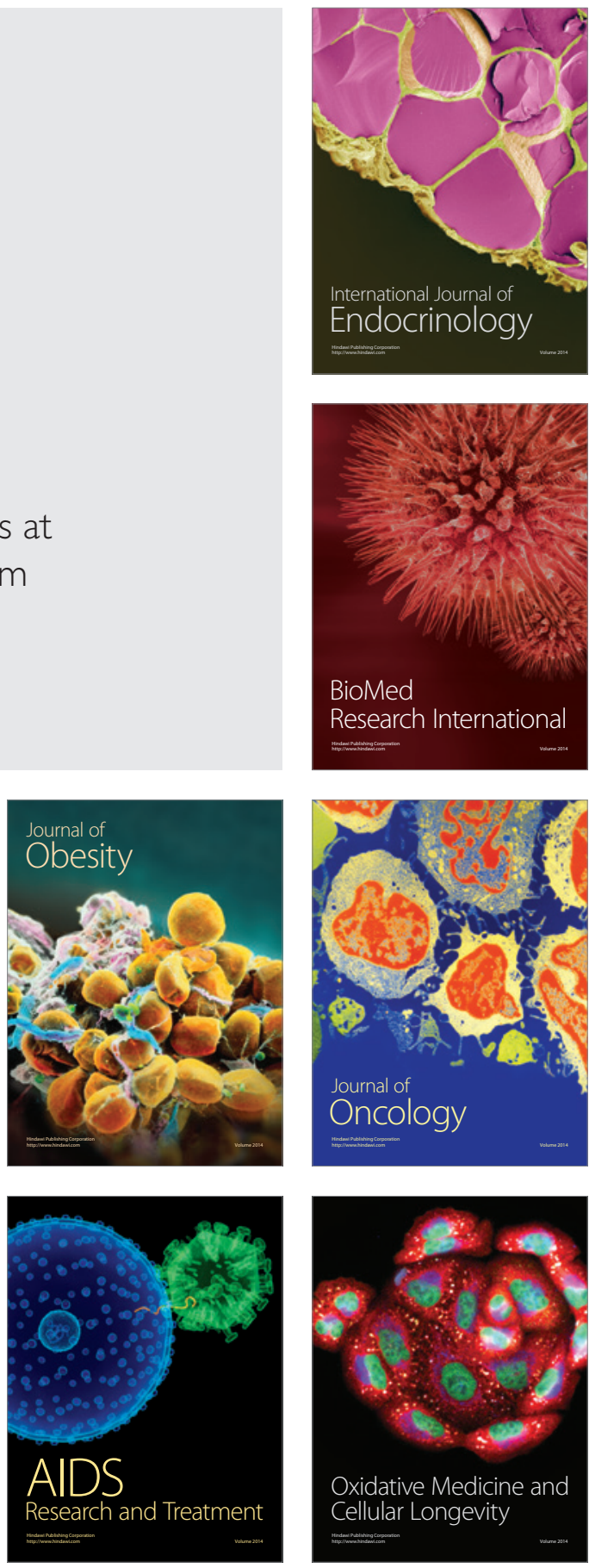